\title{
Para una psicología social crítica no construccionista: reflexiones a partir del realismo crítico de Ignacio Martín-Baró*
}

\section{For a Critic Social Psychology Non-Constructionist: Reflexions from the Critic Realism of Ignacio Martín-Baró}

Recepción: 22 Julio 2017 | Aprobación: 24 Enero 2018

\author{
Amalio Blanco \\ Universidad Autónoma de Madrid, España \\ ORCID: http://orcid.org/0000-0001-9395-2315 \\ LuIS DE LA CORTE \\ Universidad Autónoma de Madrid, España \\ José Manuel Sabucedo \\ Universidad de Santiago de Compostela, España
}

a Autor de correspondencia. Correo electrónico: amalio.blanco@uam.es

Para citar este artículo: Blanco, A., Corte, L. de la, \& Sabucedo, J. M. (2018). Para una psicología social crítica no construccionista: reflexiones a partir del realismo crítico de Ignacio Martín-Baró. Universitas Psychologica, 17(1), 1-25. https://doi.org/10.11144/Ja veriana.upsy17-1.pscc

\section{RESUMEN}

La naturaleza sociohistóricamente construida y compartida del conocimiento y de la subjetividad que el construccionismo social parece haberse arrogado en propiedad, forma parte de la historia de la ciencia social. Por otra parte, la crítica al modelo causal-mecanicista como única fuente de conocimiento, que el movimiento construccionista considera una de sus principales aportaciones epistemológicas, se remonta nada menos que a Kant. La verdadera aportación del construccionismo social ha consistido en suprimir la experiencia como fuente del conocimiento y de la subjetividad, negar la existencia de una realidad externa al sujeto, mantenerse ontológicamente mudo frente a ella y desconfiar de la posibilidad de cambiarla. Parece evidente que sobre estos cimientos no es posible, tal y como se ha pretendido, construir una psicología social crítica. Frente a ella, y en sus antípodas, el realismo crítico de Martín-Baró parte de la existencia de una realidad objetiva cuyas injusticias y miserias denunció de manera insistente, se vale de métodos cuantitativos para analizarla; la estructura social es su marco de referencia preferido a la hora de estudiar las diversas modalidades y manifestaciones del comportamiento humano, no renuncia a la existencia de verdades parciales y sociohistóricamente situadas y define como objetivo de su quehacer teórico, el cambio social.

Palabras clave

construccionismo social; realismo crítico; psicología social crítica; teoría critica.

\begin{abstract}
The sociohistorically built and created nature of knowledge and subjectivity that social constructionism seems to have arrogated is part of the history of social science. Moreover, criticism to the casual mechanistic model as the only source of knowledge \#that the constructionist movement considers as one of its main epistemological contributions\# goes back to none other than Kant. The real contribution of social constructionism has consisted in deleting experience as a resource for knowledge and subjectivity, denying the existence of an external reality
\end{abstract}


to the subject, keeping ontologically quiet towards it, and distrusting the possibility of changing it. It seems evident that building a critical social psychology upon these foundations is not possible. Opposing this, MartinBaró's critical realism is based on the existence of an objective reality of which injustices and wretchedness he insistently denounced. This critical realism makes use of quantitative methods to analyze this objective reality, it holds social structure as its preferred framework when studying the different modalities and manifestations of human behavior, it does not deny the existent of partial and sociohistorically situated truths, and it identifies social change as the objective of its theoretical work.

Keywords

social constructionism; critical realism; critical social psychology; critical theory.

A estas alturas del desarrollo de las ciencias sociales, caben pocas dudas de que los términos en los que venimos a conocer el mundo que nos rodea no son producto de la naturaleza, sino construcciones sociales ("social artifacts") resultado de relaciones de intercambio activo y cooperativo entre las personas, como reza el segundo de los principios del construccionismo social (Gergen, 1985, p. 267; Gergen, 1996, p. 73; Gergen, 2015, p. 9). Pero al mismo tiempo, recordando con ello el principio de irreductibilidad del Lewin más gestáltico, convendremos también que estas construcciones pertenecen a "un nivel onto-epistémico irreductible a lo interpersonal, $\mathrm{y}$, por supuesto, a lo individual" (Jiménez Burillo, 2005, p. 6). Ese nivel de realidad está acompañado además de otros tres: el fisicoquímico, el más elemental; el biológico y el cultural. Entre ellos no hay "ruptura ontológica", sino continuidad, intercambio, interdependencia y mutua influencia, procesos todos ellos que conforman el núcleo duro de la perspectiva psicosocial. Esta se ubica de manera preferente en el tercero de los niveles (vida inteligente, nivel mental, nivel social, son las denominaciones propuestas), pero su razón de ser no solo no excluye, sino que requiere y necesita la presencia de los niveles previos alejándose así de viejos dualismos respecto a los que el mismísimo Kant dictó sentencia en la obra cumbre de la filosofía moderna, la Crítica de la razón pura. Siendo, pues, el nivel social en sus conexiones con los procesos mentales (la subjetividad) nuestra principal preocupación, no parece sensato pasar por alto los términos en los que este se materializa en la cultura y en el orden y la estructura macro y microsocial en la que se desenvuelve la vida de las personas con las consecuencias que de ello pueden derivarse a través de valores y creencias culturales, pautas de socialización diferencial, modelos de relación interpersonal e intergrupal, etc. Estos son los términos en los que pretendemos desarrollar este artículo: la necesaria interdependencia entre los niveles objetivos y subjetivos de realidad; la necesidad de tomar en consideración las consecuencias que de ellos se derivan y de tomar partido respecto a su permanencia o su cambio. En todos estos ámbitos, la posición epistemológica de Ignacio Martín-Baró será obligado punto de referencia.

\section{La necesaria interlocución entre sensibilidad y entendimiento}

En un corto ensayo sobre la teoría del conocimiento del materialismo dialéctico escrito en 1963, Martín-Baró deja planteadas dos propuestas que volveremos a encontrar, más elaboradas, en sus formulaciones teóricas de madurez. En la primera de ellas, y en abierta contraposición con la principal tesis del materialismo, afirma la existencia de "seres reales que no son materia" (Martín-Baró, 2016, p. 85). El psicólogo social que devendrá después los agrupará alrededor de la ideología y sorprenderá a propios y extraños con esa heterodoxa definición de la psicología social como "el estudio científico de la acción en cuanto ideológica" (MartínBaró, 1983, p. 17). Al defender la existencia real de entes que carecen de un sustrato material, el estudiante de filosofía cree haber quedado inmunizado contra el idealismo: "estamos lejos de toda sombra de idealismo", afirma rotundo (Martín-Baró, 2016, p. 86).

Siguiendo la huella de Santo Tomás (todo ser es "inteligible en potencia"), en la segunda de las propuestas sostiene que la naturaleza cognoscible de todo ser no implica que su existencia quede 
encapsulada en el hecho de su cognoscibilidad, sino que "su realidad, su existir es indiferente a que lo conozcamos o no" (Martín-Baró, 2016, p. 88). La existencia de una realidad que pasa desapercibida a nuestra conciencia haciéndose visible por sus consecuencias en los distintos niveles del comportamiento interpersonal e intergrupal constituye hoy el eje de una larga y sostenida tradición investigadora en el campo del procesamiento automático e inconsciente de la información (Dijksterhuis, 2010), que pone seriamente en aprietos la (peregrina) idea de que cuando no hay lenguaje y conversación, la acción entre los interlocutores carece de significado (Gergen, 2011 entrevistado en Aceros, 2011, p. 1007) y, por tanto, de consecuencias.

Nos encontramos ante dos argumentos de largo alcance, que sitúan a su autor muy lejos del construccionismo social $^{1}$ y acaban poniendo de manifiesto una clara falta de entusiasmo de aquel estudiante de apenas 21 años por los dualismos excluyentes a los que acabaron sucumbiendo naturalismo e idealismo, para dejar insinuada su apuesta por un flujo continuo entre subjetividad y objetividad en una suerte de síntesis dialéctica cuyo principal postulado será el principio de interacción mutuamente constitutiva entre el ser humano (subjetividad) y la sociedad (Martín-Baró, 2016, p. 191). Los primeros pasos, algo tímidos, los dará en "Sufrir y ser", otro ensayo de juventud (Martín-Baró, 2016). Su desarrollo más sistemático y con mayor conocimiento de causa llegará años después, en plena madurez, siguiendo un sencillo argumento: no se pueden obviar los condicionamientos objetivos de la subjetividad, porque, a pesar de que "no sea visible y con frecuencia resulte de difícil o cuestionable medición, no quita para que constituya una realidad objetiva, conocida o no" (Martín-Baró, 2016, p. 206).

Esos condicionamientos nos remiten al "carácter estructural e histórico de las realidades y los actos humanos [y] nos alejan de todo tipo de reflexión ética idealista que no tome ese carácter en cuenta en una forma directa e inmediata", escribiría en otro ensayo de juventud (Martín-Baró, 2016, p. 198). Junto a lo histórico, que el construccionismo social prioriza y que hace más de cien años nadie pone en tela de juicio, lo estructural, que es donde lo social encuentra regularidad y constancia, algo que el construccionismo rechaza por principio. Desde su punto de vista, y por dejarlo resumido con una gruesa pincelada, las cosas irían, alternativa e indistintamente, del cielo (prioridad epistemológica de los productos de la razón: lo primario es el espíritu; la realidad queda reducida a la idea) a la tierra (lo primario es la materia, los hechos susceptibles de observación a través de los órganos de los sentidos), y de la tierra (explicaciones basadas en hechos empíricamente comprobados que dan lugar a leyes universales) al cielo (descripciones basadas en percepciones e interpretaciones subjetivas de la realidad apoyadas en convenciones lingüísticas), por recordar la conocida metáfora de Marx y Engels en Feuerbach. Oposición entre las concepciones materialista e idealista.

En el marco epistemológico de la psicología social, esta postura no reviste novedad alguna. Ese fue el trayecto que siguieron, por ejemplo, Kurt Lewin en su Epistemología Comparada (Lewin, 1991), Lev Vygotski en su "síntesis dialéctica” (Vygotski, 1931/1995) y George H. Mead en sus sucesivas y nunca bien ponderadas aproximaciones al estudio de la conciencia del significado, y del principal de todos ellos, el "self" (Mead, 1964, 1972). No son los únicos que apostaron de manera decidida por la superación de esa epistemología de dirección única a la que acabaron sucumbiendo el materialismo empirista y el racionalismo idealista, y a la que ahora rinde culto el construccionismo social. Max Horkheimer también lo hizo. Nos interesa de manera especial su postura no solo porque es una de las figuras más señeras del pensamiento filosófico del pasado siglo, sino por ser el más cualificado representante de la teoría crítica: en realidad, el naturalismo no está radicalmente equivocado, porque "el espíritu está indisolublemente unido con su objeto, la naturaleza" (no hay ruptura ontológica entre los niveles de realidad), de suerte que todo proceso psíquico ("acto espiritual" es la expresión que utiliza) "implica algún tipo de materia o naturaleza". Presentado como un 
absoluto, el espíritu y sus productos (las ideas, los significados, los relatos, el lenguaje, los repertorios interpretativos) devienen en puro mito, escribía en La crítica de la razón instrumental (1947), una las obras más emblemáticas del pasado siglo (Horkheimer, 2002, p. 176). Recordemos que ese fue precisamente el argumento de Marx contra la "mistificación" que sufre la dialéctica en manos de Hegel: la idea convertida en demiurgo de lo real.

Todo esto es cierto, pero sería injusto no recordar, y reconocer, que, en su origen, la relación de interdependencia y mutua influencia entre el yo y el mundo, la naturaleza y la historia, la biología y la cultura, etc., tiene como referente indiscutible la síntesis entre racionalismo y empirismo con la que, de manera lapidaria, da comienzo la Crítica de la razón pura cuya primera edición data de 1781. En ella, Kant intenta congraciar las dos tendencias aparentemente antagónicas entre las que se había debatido hasta ese momento la teoría del conocimiento: el racionalismo metafísico de Descartes y el realismo de los empiristas ingleses, con Bacon a la cabeza: "no se puede dudar que todos nuestros conocimientos comienzan con la experiencia", con la activación de nuestros sentidos ante la estimulación de un determinado objeto; pero no todos ellos proceden de dicha experiencia, "pues bien podría suceder que nuestro conocimiento empírico fuera una composición de lo que recibimos por las impresiones y de lo que aplicamos por nuestra propia facultad de conocer" (Kant, 1994, p. 98. Las cursivas son nuestras), de lo que el sujeto propiamente dicho pone de sí mismo (su manera de percibir e interpretar la realidad).

El conocimiento es al mismo tiempo fruto de la experiencia (hechos, datos e impresiones sensibles que surgen al contacto con los objetos de la realidad: pensamiento empírico) y de los pensamientos e ideas que, al margen de ella, pone de su parte ("aplica") el sujeto: hay conocimientos a priori (conocimiento puro) que son "absolutamente" independientes de la experiencia. Junto al conocimiento "reglado por los objetos", Kant admite la posibilidad de que sea la experiencia la que pueda regularse por los conceptos (posibilidad de un conocimiento a priori al margen de los objetos). Ambas, sensibilidad (capacidad de recibir representaciones de los objetos) y entendimiento (capacidad de producir representaciones, de pensar sobre los objetos) resultan imprescindibles en la tarea del conocimiento: "el entendimiento no puede percibir y los sentidos no pueden pensar cosa alguna. Solamente cuando se unen resulta el conocimiento", de suerte que "pensamientos sin contenido, son vacíos; intuiciones sin conceptos, son ciegas", dirá en la Introducción al capítulo dedicado a la lógica trascendental (Kant, 1994, p. 132). Aplicado a la psicología, ya en la década de los 30 del pasado siglo, el mismísimo Vygotski (1995) había postulado algo muy parecido: no es posible una psicología sometida a la tiranía de la razón, que se permita el lujo de prescindir de la mente, de la conciencia, del significado, ni una psicología tiranizada por la subjetividad, que defienda la existencia de una psique (conciencia) en estado puro, ingrávido, ajena a cuanto sucede a su alrededor. Se hace necesaria una síntesis dialéctica.

Cabría decir, pues, que Kant fue el primer crítico del modelo causal-mecanicista del conocimiento humano; fue realmente quien puso contra las cuerdas las bases objetivas del conocimiento convencional (el realismo baconiano), y no el movimiento construccionista como afirma Gergen (1985, p. 267). La cuestión que se dilucida, según consta en el Prefacio a la primera edición de la Crítica de la razón pura, es nada menos que la existencia de conocimiento "sin valerse de la experiencia"; la posibilidad de una "razón extraempírica", de suerte que cuando Kenneth Gergen afirma en el primero de los supuestos del construccionismo social, que no es la experiencia la que define los términos de nuestra comprensión del mundo (Gergen, 1985, p. 266), volvemos literalmente a Kant. A pesar del escaso protagonismo que Gergen le concede, el verdadero adalid de la crítica a la antinomia entre las perspectivas "exogénicas" y endogénicas" es el filósofo de Könignsberg. Sin embargo, contrariamente a lo que el propio autor sostiene (Gergen, 1985, p. 271), en el transcurso de su desarrollo, el construccionismo no ha trascendido esa antinomia, sino que ha ahondado 
insistentemente en ella posicionándose al lado de la perspectiva endogénica y ha acabado por abrir una brecha prácticamente insalvable entre ambas posiciones. Primero, reduciendo la realidad a la cognoscibilidad y encapsulándola en convenciones lingüísticas y poniendo en cuestión después la experiencia sensible (Gergen, 1985, p. 272).

\section{El giro epistemológico}

La naturaleza socio-históricamente construida y compartida del conocimiento y de la subjetividad humana ha contado con valedores de postín al menos desde La pobreza de la filosofía de Marx, escrita en 1846, la Introducción a la dialéctica de la naturaleza de Engels, que data de 1875 y, sobre todo, desde que en 1883 Dilthey publicara la Introducción a las ciencias del espíritu. Si a Kant le correspondió dar un vuelco a la teoría del conocimiento, Dilthey será el encargado de darle un giro epistemológico, abriendo el camino a la diferenciación entre las ciencias naturales y las ciencias sociales (una aberración en toda regla para Kant) y de concederle carta de naturaleza (estatus epistemológico) a la autonomía de estas últimas ("las ciencias del espíritu forman un sistema autónomo en sí mismo", escribe en el Prólogo al primer volumen de la Introducción a las ciencias del espíritu). Las denominadas ciencias del espíritu no se sitúan "frente" sino "al lado de las ciencias de la naturaleza", y lo hacen en una clave que bien merece la pena recoger en su integridad: "el material de estas ciencias está constituido por la realidad histórico-social en la medida en que se ha conservado como noticia histórica en la conciencia de la humanidad y en la medida en que se ha hecho accesible a la ciencia como noticia acerca del estado actual de la sociedad" (Dilthey, 1985, p. 57).

Se trata de una clave que hoy en día damos por sólidamente asentada en el campo de las ciencias sociales como reacción al reduccionismo biologicista y mecanicista en las explicaciones de la vida social, del comportamiento y de la psique (subjetividad) humana. Aunque el receptáculo de esa huella no puede ser más que la conciencia individual, no por eso deja de ser al mismo tiempo, debido precisamente a sus raíces histórico-sociales, una huella que afecta a las personas en una de sus dimensiones psicosocialmente más relevantes: su pertenencia grupal (en términos macro o microsociales) y categorial; una huella compartida cuya marca perdura gracias a la (relativa) constancia y regularidad (estabilidad) del orden y la estructura que caracteriza a cualquier entidad supraindividual en forma de normas, preceptos, leyes, valores, costumbres, tradiciones, creencias, etc. Superadas ya las viejas hipótesis de un "Volkgeist" al estilo germano del Wundt de la Psicología de los pueblos o de una "group mind" al estilo de William McDougall o Charles Ellwood, en la psicología social actual tenemos sobradas noticias de esa huella a través de los contenidos de la cognición socialmente situada (Semin \& Smith, 2013) y socialmente compartida (Thomson \& Fine, 1999), ejemplos de conocimiento apriorístico y de razón extraempírica en el sentido kantiano, que dan cobertura a problemas de tanta relevancia social como el racismo, la xenofobia, el antisemitismo, la homofobia, el machismo y un largo y preocupante etcétera.

Este hecho tan elemental e incontrovertible convierte una parte de la realidad subjetiva en una realidad parcialmente objetiva, que ciertamente plantea serios problemas al método usado por las ciencias naturales $^{2}$. A Ortega y Gasset, por ejemplo, le parecieron tan graves que los llega a identificar con la crisis de la modernidad de la que ya empezaba a hablarse en su tiempo. Perdida la fe en la razón ilustrada, queda abierto el camino para la potenciación de una racionalidad histórica: "ha llegado el momento de que la razón que era solo física se libere de esta limitación y de que el hombre crea en la razón histórica" (Ortega y Gasset, 1983, p. 329). Ese mismo modelo de razón es el que aparece como argumento nuclear en la Sociología del conocimiento de Karl Mannheim, primero, y posteriormente de Robert Merton. $\mathrm{Su}$ tesis principal, formulada en otra de las obras emblemáticas del pensamiento social del pasado siglo, Ideología y utopía, tiene un aire muy psicosocial: las formas y los productos 
del conocimiento "no se pueden comprender debidamente mientras permanezcan oscuros sus orígenes sociales" (Mannheim, 2004, p. 34). Formulada en estos términos tan diáfanos, esta tesis, tan amigable al construccionismo social, se despliega en no menos de tres poderosos supuestos que, sin embargo, acaban por alejarse de sus principales argumentos.

El primero de ellos alude a la naturaleza colectiva en la génesis de las ideas, de los juicios sintéticos a priori, si seguimos el camino trazado por Kant: es un error creer que los pensamientos y emociones que mueven a la acción tienen su origen en el individuo y "que pueden explicarse adecuadamente a base solo de la experiencia de su propia vida”. Esta hipótesis se apoya en la débil "ficción del individuo aislado y capaz de bastarse a sí mismo", en palabras de Max Horkheimer; tiene como protagonista a un ser humano incapaz de ser concebido "dentro de una esfera de interioridad estática”, en emblemática expresión de Berger y Luckman, y contraviene la absolutez del yo como sujeto soberano de conocimiento en la que se ha instalado el construccionismo social, que acabará por empequeñecerse en la absolutez del lenguaje como única fuente de conocimiento, como única realidad y como única línea de acción.

En realidad, quienes piensan no son individuos solitarios, sino que, según Mannheim (2004, p. 35), son personas "que pertenecen a ciertos grupos y que han desarrollado un estilo particular de pensamiento en una interminable serie de respuestas a ciertas situaciones típicas que caracterizan su posición común", que no se reduce a compartir meras "reglas de interpretación” (Gergen, 1996, p. 316), sino que se traduce en reglas que definen sentimientos y acciones (las normas y emociones intergrupales, sin ir más lejos) que dejan una huella perfectamente objetivable en la vida de las personas (basta para ello pensar en el rastro que ha dejado la violencia colectiva en América Latina). Esta posición es irreductible a la postura que puedan adoptar a título individual las personas pertenecientes a esos grupos, siguiendo uno de los principios más elementales de la teoría de la Gestalt, que tanta influencia tuvo en la teoría lewiniana a la que el propio Gergen (1985, p. 269) le concede un papel protagónico en la implantación de una perspectiva "endogénica", a través del énfasis que algunos de sus discípulos (Festinger y Schachter) hicieron en la importancia de la cognición, pero parece hacerlo sin prestar la debida atención a las consecuencias, visibles, medibles y cuantificables de la cognición socialmente compartida (el ejemplo de la violencia colectiva sigue siendo válido).

Todos los contenidos y formas que adquiere nuestro conocimiento tienen, en segundo lugar, un referente histórico; se sitúan de manera inevitable "dentro del marco de una situación histórico-social de la cual emerge poco a poco el pensamiento individualmente diferenciado" (Mannheim, 2004, p. 35), dando cuenta fehaciente del "arraigo del conocimiento en la textura social" o, lo que es lo mismo, de la prevalencia del ser sobre el pensar, que será una de las líneas maestras de la teoría crítica (Horkheimer, 1974) y de las ineludibles relaciones entre el conocimiento y sus factores existenciales (fundantes) a los que Robert Merton, con Marx al fondo, prestará una especial atención. La base existencial de las producciones mentales tiene su origen en dimensiones sociales (la estructura: posición social, clase, generación, rol ocupacional, modo de producción, estructuras grupales, situación histórica, estructura de poder, etc.) y culturales (valores, ethos, clima de opinión, tipo de cultura, visión del mundo, etc.) (Merton, 1977, p. 52). De entre ellas, "los estudiosos de la vida intelectual han destacado la influencia corruptora de las lealtades grupales" (Merton, 1977, p. 184), presente siempre en la construcción del conocimiento y de la acción humana de las que el construccionismo no es una excepción.

En tercer lugar, y como consecuencia (o como fundamento) inevitable de todo ello, hace acto de presencia la naturaleza construida del orden social (Berger \& Luckman, 1968) o del desorden ordenado (Martín-Baró, 1989a, pp. 13-90). Aunque sobradamente conocida y reiteradamente comentada, conviene volver a recordar los términos de la argumentación de 
Berger y Luckman: a) el orden social no se da ni se deriva de datos biológicos ni de leyes de la naturaleza; solo existe como fruto de la actividad humana. Al mismo tiempo, y debido a la relación de interdependencia y mutua influencia entre los distintos niveles de realidad, "la necesidad del orden social en cuanto tal surge del equipo biológico del hombre". En su historia psicosocial de la violencia, el propio Martín-Baró (1983), poco sospechoso de veleidades biologicistas, alude al ser humano como "un ser abierto a la violencia y a la agresión como posibilidades comportamentales que tienen su base en la configuración del propio organismo" (p. 405); b) los fenómenos típicamente humanos no tienen lugar en la interioridad estática del sujeto, sino en el dominio de lo social: "el homo sapiens es siempre, y en la misma medida, un homo socius"; c) el desarrollo individual (la subjetividad) está precedido por un orden social; cuando este se institucionaliza, se experimenta como algo que existe "por encima y más allá de los individuos a quienes acaece" encarnar las instituciones en los distintos momentos de la historia (Berger \& Luckman, 1968, pp. 72-80). El intercambio activo y cooperativo que da lugar a las ideas y teorías con cuya ayuda conocemos e interpretamos la realidad (Gergen, 1985) son fruto de una "tipificación recíproca de acciones", cuyas características más sobresalientes son la habituación, la regularidad, la estabilidad; en una palabra, la institucionalización (Berger \& Luckman, 1968, p. 76).

Cuando desde la ciencia social hablamos de la génesis colectiva de las ideas, del marco histórico-social de los contenidos y formas del conocimiento (Mannheim) y de la conciencia (Dilthey), de la naturaleza "creada" del orden social y de su base ideológica (la cultura), emerge de manera inevitable la genial figura de Lev Vygotski. La razón histórica o, si se prefiere, la razón histórico-social o histórico-cultural, que para el caso vienen a ser lo mismo, que tiene en la falacia del individuo aislado, solitario y autosuficiente (en la absolutez del yo propia del construccionismo social) de Horkheimer, Mannheim, Elias, Berger y Luckman, etc., su más acabado ejemplo, encuentra en Lev Vygotski un sólido apoyo epistemológico y un original respaldo en el campo de la investigación, ahora ya en el seno de la propia psicología. Dicho apoyo se muestra especialmente crítico con el biologicismo mecanicista incapaz, a su entender, de considerar el desarrollo de las funciones psíquicas superiores "como hechos del desarrollo histórico" al concebirlos "como procesos y formaciones naturales, confundiendo lo natural y lo cultural, lo natural y lo histórico, lo biológico y lo social en el desarrollo psíquico del niño"; confusiones todas ellas que abonan el camino para "una comprensión radicalmente errónea de la naturaleza de los fenómenos que estudia" (Vygotski, 1995, p. 12). La solución no pasa precisamente por la psicología comprensiva, representada en la actualidad por el construccionismo, porque sustituye las leyes universales de la naturaleza por las leyes universales del espíritu, ignora las diferencias entre lo natural y lo cultural y es asocial: habla mucho de historia, pero "se niega a reconocer la simple verdad de que el desarrollo histórico es el desarrollo de la sociedad humana y no del puro espíritu humano, que el espíritu se ha desarrollado a la par que se ha desarrollado la sociedad". En una palabra, más que enmarcar en un contexto histórico el desarrollo psíquico de la persona, la psicología idealista "lo que hace es declarar que la historia es el reino del espíritu" (Vygotski, 1995, p. 27).

El "postulado acerca del desarrollo sin cambios en el tipo biológico", y la "ley genética del desarrollo cultural", que preparan el camino a la tesis por excelencia de la teoría sociocultural (la "sociogénesis de la formas superiores de conducta"), son epistemológicamente deudoras de la razón histórica: el mecanismo que subyace a las funciones psíquicas superiores es una copia de lo social (Vygtoski, 1995, p. 151), es decir, del desarrollo histórico, porque es en la historia como praxis donde tiene su origen el desarrollo de la sociedad humana. Por varias razones: primero, porque, contrariamente a lo que ocurre con las funciones psíquicas superiores, las funciones psicofisiológicas elementales apenas si se modifican en el transcurso del devenir histórico (Vygotski, 1995, p. 27); después, porque 
cuando hablamos del desarrollo cultural de la persona aludimos al desarrollo psíquico que se produce a lo largo de un determinado momento del desarrollo histórico (Vygotski, 1995, p. 35), y, finalmente, porque en su ontogenia, las funciones psíquicas (la subjetividad) nos remiten en un primer momento al plano de lo social y solo después se consolidan como categoría intrapsíquica propiamente dicha, según reza la sobradamente conocida ley genética del desarrollo cultural, vale decir, del desarrollo psíquico: "toda función en el desarrollo cultural del niño aparece en escena dos veces, en dos planos; primero, en el plano social, y después en el psicológico, al principio entre los hombres como categoría interpsíquica y luego en el interior del niño como categoría intrapsíquica" (Vygotski, 1995, p. 150).

Realmente, sin pretenderlo de manera explícita, además de una severa crítica a las posiciones idealistas, Vygotski nos ha proporcionado algunos argumentos para establecer una correspondencia entre el mecanicismo positivista y el idealismo construccionista: ambos parten de posturas exclusivas y excluyentes manteniendo, así, una "ruptura ontológica" entre los distintos niveles de realidad y prescindiendo de procesos tan psicosociales como la interacción, la interdependencia y la mutua influencia entre ellos. Ambos apelan de manera permanente a categorías universales. De algún modo, la razón natural del positivismo y la subjetivización de la razón que propicia el construccionismo es la misma razón universal, necesaria y sustancialista. Donde el positivista ve exclusivamente hechos y cosas, el construccionista solo ve significados $y$, a la postre, en ambos casos el acceso a la realidad queda limitado y parcialmente oscurecido. El dato (positivismo) y el significado (construccionismo) se convierten en fetiche. $\mathrm{Si}$ el respeto a lo dado es la religión fetichista del positivismo, el respeto reverencial a lo pensado en la interioridad del sujeto cognoscente se convierte en el nuevo fetiche del constructivismo.

Ambos desatienden la influencia de la estructura social y de sus efectos sobre la vida y la experiencia de las personas. En ambos casos, con especial énfasis en el construccionismo social, se produce una escisión injustificada entre lo histórico-cultural y lo estructural. Desde ambas posiciones, la persona se convierte en la única unidad de análisis contraviniendo, así, uno de los principios rectores de la perspectiva psicosocial: la importancia del contexto y de la situación. Así, el individualismo psicologicista que las define refuerza las estructuras sociales con independencia de lo injustas, violentas, deshumanizantes u opresivas que sean. Cuando se reduce a la individualidad lo que solo acontece en la dialéctica de las relaciones interpersonales, "el individualismo termina reforzando las estructuras existentes al ignorar la realidad de las estructuras sociales y reducir los problemas estructurales a problemas personales" (MartínBaró, 1998, p. 291). Además, el positivismo pone el conocimiento al servicio del cálculo, la utilidad, el resultado (la razón instrumental); el construccionismo lo pone al servicio de cualquier empeño particular. La razón subjetiva acaba convertida en una razón instrumental puesta al servicio de intereses personales, una suerte de pragmatismo individualista: "la razón subjetiva se acomoda a todo. Ofrece sus servicios tanto a los adversarios de los valores humanitarios tradicionales como a sus defensores" (Horkheimer, 2002, p. 62). El interés egoísta se convierte, pues, en una seña de identidad común y la utilidad o la satisfacción del sujeto se erigen en el criterio de verdad (Horkheimer, 2002, p. 83).

\section{Algunas conclusiones espurias de la psicología social como empresa histórica}

Es en este marco en el que cabe incluir la propuesta que Kenneth Gergen hiciera a comienzos de la década de los setenta al definir la psicología social como una forma de historia. Fue realmente una apuesta valiente, pero tuvo poco de original, porque su principal argumento, el de que la psicología social es un quehacer histórico debido a la naturaleza abierta e inestable de los hechos de los que se ocupa y a su fluctuación 
y cambio en el transcurso del devenir histórico (Gergen, 1973, p. 310), nos remite, como acabamos de ver, al núcleo duro del materialismo dialéctico, a la filosofía comprensiva de Dilthey, a la teoría crítica de la Escuela de Frankfurt, a la sociología del conocimiento y a la teoría sociocultural.

Todas estas propuestas, cada una a su manera, ponen en tela de juicio la posibilidad de elaborar leyes de validez transhistórica y universal, a la hora de abordar asuntos relacionados con la vida social o con el comportamiento humano; todas se distancian de la acumulabilidad del conocimiento en el sentido de que a este principio se le ha dado en la ciencia natural y aceptan el supuesto de que la ciencia es algo más que la mera acumulación de datos; se muestran igualmente críticas con el modelo de sujeto individualista, hedonista y ahistórico que ha (des)dibujado el positivismo y admiten la naturaleza construida de la realidad social como resultado de prácticas y transacciones humanas históricamente situadas; todas convendrían igualmente en la naturaleza transitiva de los hechos de los que se ocupa la ciencia social, es decir de su dependencia del significado que las personas le atribuyen y de la posibilidad de modificarlos como consecuencia del cambio en los significados atribuidos; todas abren también la puerta a métodos alternativos de investigación, por entender que los métodos experimentales y de laboratorio pretenden "cerrar" artificialmente una realidad que es "abierta" por naturaleza; en todas ellas, de manera implícita o explícita, hay una crítica a la posibilidad de una ciencia libre de valores; además, no dudan que el conocimiento científico genera perspectivas teóricas de validez solo parcial debido a las limitaciones cognitivas de nuestra mente, que hacen imposible aprehender en un solo intento (ni en un número finito de ellos) todas las variables causales que contribuyen a la producción de los fenómenos que tratan de explicar. Finalmente, es importante señalar que todas ellas, distanciándose claramente del construccionismo, dan por supuesta la utilidad del conocimiento, una suerte de racionalidad científica, que acude en nuestra ayuda a la hora de dar respuesta a problemas sociales.

El problema que plantea la postura del construccionismo social no lo constituyen los argumentos (nada novedosos, insistimos) de los que se sirve, sino la naturaleza apodíctica de su formulación: los hechos de los que se ocupa la psicología social carecen de regularidad; los conceptos y teorías que manejamos tienen un carácter prescriptivo (sesgo valorativo): indican, de manera políticamente interesada, lo que es preferible y/o socialmente deseable; las teorías psicosociales son herramientas para el ejercicio del poder y del control social; la conducta humana no es previsible, y cuando se pretende hacerla, coloca a las personas en una situación de especial vulnerabilidad; la subjetividad humana es la única fuente fiable de conocimiento; no hay posibilidad de elaborar leyes generales sobre la conducta social; la observación empírica no genera una comprensión teórica de los fenómenos psicosociales; la psicología actual no tendrá ningún valor en el futuro; los académicos tienen un acendrado prejuicio contra la aplicación; la única limitación de la teoría es la que fija las convenciones del lenguaje; la psicología y la psicología social no pueden ser ciencias positivas; la experiencia y los datos procedentes de los órganos de los sentidos no forman parte del contenido de la subjetividad; los estudios experimentales son socialmente vacíos y tan solo han servido para dar alas al poder opresor, y así sucesivamente.

Puesto que la experiencia no es la única fuente de conocimiento, esta queda reducida a meras convenciones lingüísticas; como la realidad se nos presenta de manera engañosa, la realidad no existe más allá de las ideas que tengamos sobre ella; puesto que no existe una verdad universal, la verdad no existe. La supuesta mudez ontológica (la razón depurada hasta el extremo de "renunciar incluso a la tarea de enjuiciar acciones y modos de vida de los seres humanos", en palabras de Horkheimer, 2002 , p. 50) y la renuncia a todo criterio de verdad, dos de los supuestos más sobresalientes del constructivismo, no salen precisamente muy reforzados a partir de estos enunciados enfáticos 
con vocación de eternidad: "la verdad no existe; he ahí la verdad”. No es nuestra intención entrar en el debate de cada uno de estos temas, pero algunos de ellos merecen una especial atención.

La naturaleza políticamente perversa que acompaña al sesgo valorativo, por ejemplo, empieza a diluirse cuando, en vez de poner el foco de atención en la conformidad o en el autoritarismo, hablamos de discriminación, racismo, violencia, exclusión, etc. Entonces, las prescripciones pierden el carácter indómito que Gergen les atribuye para convertirse en instrumentos de intervención capaces de responder a esa noble tarea que George Miller le atribuía a la psicología: ser un instrumento al servicio del bienestar humano (Miller, 1969). Martín-Baró se sumaría a esta posición en unos términos que ofrecen pocas dudas respecto a su postura abiertamente distante del construccionismo social: la psicología se interesa y se introduce en los campos de la familia, las relaciones laborales, la educación, etc., "como un intento expreso de humanización, de crecimiento humano y cultural: se trata de comprender mejor a las personas, de entender más a fondo aquellos aspectos que permiten a los seres humanos lograr una vida mejor, de profundizar en el planteamiento más adecuado de aquellos problemas que enfrentan a los individuos y los grupos y les impiden su desarrollo y plenitud” (Martín-Baró, 2016, p. 181).

Claro es que, al mismo tiempo, la psicología puede servir, y ha servido de hecho, para todo lo contrario: para aplicar con éxito la tortura; para controlar y castigar a los disidentes; para justificar la guerra, el machismo, la xonofobia, el racismo y largo etcétera (la psicología al servicio del poder: véase Teo, 2015, pp. 246-247) contraviniendo así su propia racionalidad científica y su propia racionalidad ética. Solomon Asch, por recordar una de las investigaciones paradigmáticas, nos enseñó que el conocimiento psicológico procedente de estudios experimentales puede servir tanto para fomentar la sumisión y el control social como la autonomía, y en las conclusiones de sus estudios hace una crítica severa a los modelos de grupo y sociedad basados en la conformidad (Asch,
1964, pp. 492-498). Stanley Milgram llevó a cabo sus 18 experimentos sobre la obediencia a la autoridad estremecido por el torrente de muerte y destrucción producido por el antisemitismo nazi y espoleado por las declaraciones de Adolph Eichman declarándose como un simple servidor del Estado.

En los estudios de Milgram, podemos encontrar argumentos para la obediencia y para la rebelión (véase, por ejemplo, el experimento 17: Milgram, 1980, pp. 113-118). El famoso estudio de la prisión de Stanford estuvo presidido por una severa crítica al sistema penitenciario norteamericano: a su ineficacia, al maltrato a que estaban sometidos los presos en muchas de ellas, a su incapacidad para cumplir el objetivo, probablemente iluso, de rehabilitación, a su incapacidad para afrontar con garantías el problema de la criminalidad en Estados Unidos (Haney \& Zimbardo, 1998). Los experimentos sobre la impasibilidad del espectador (Latané \& Darley, 1971) parten de la preocupación de los autores por la inhibición de los residentes de un bloque de apartamentos ante la petición de ayuda de una vecina atacada ( $y$ finalmente asesinada) por un individuo. La intención de Jost y Banaji (1994; Jost, Banaji, \& Nosek, 2004) no es fomentar la explotación, la desigualdad y la injusticia social, sino todo lo contrario: desvelar los mecanismos que sirven para la justificación y mantenimiento de un statu quo y del orden social que las favorece y las alienta ${ }^{3}$.

El objetivo de Lippitt y White (1973) tampoco fue ensalzar los estilos autoritarios de liderazgo, sino mostrar las ventajas del liderazgo democrático; y las investigaciones de Susan Fiske están claramente dirigidas a denunciar el sexismo ambivalente (Glick \& Fiske, 1996). Otro tanto podríamos decir de los estudios procedentes de la rica tradición empírica en torno al prejuicio (Allport, 1962), al prejuicio sutil (véase al respecto la interesante reflexión teórica de Dovidio, 2001) o a la infrahumanización (véase la revisión de Rodríguez, Rodríguez, \& Leyens, 2003): su intención no es fomentar esas conductas, sino denunciarlas. Por no hablar de las propuestas de Moscovici (1976) sobre la capacidad de innovación de las minorías 
activas, o las de Sherif y Sherif (1953) para ofrecer soluciones al conflicto intergrupal. Un ejemplo especialmente significativo nos lo ofrece Morton Deutsch, uno de los discípulos más entusiastas de Lewin, en el corto pero suculento repaso de su vida académica. Sus estudios sobre las relaciones cooperativas y competitivas, la reducción del prejuicio o la justicia distributiva son excelentes ejemplos del compromiso social de la investigación experimental (Deutsch, 1999).

En pocas palabras, la psicología crítica no renuncia al potencial transformador de la investigación empírica, con Kurt Lewin y MartínBaró como ejemplos (Teo, 2015, p. 248). Por estas y otras muchas razones (ejemplos de líneas de investigación) que se podrían haber aducido, decir que la psicología social tradicional "forma parte de un todo un andamiaje cultural dirigido a ocultar las contradicciones e injusticias sociales" (Ovejero \& Ramos, 2011, p. 22) no parece que responda de manera fidedigna a lo que ha sido el desarrollo de una parte muy significativa de esta disciplina. Claro es que ni a Deutsch ni a nadie mínimamente avezado en los contenidos de la psicología social se le puede ocultar que hay estudios experimentales carentes de interés teórico y alejados de cualquier asomo de compromiso social (Deutsch pone como ejemplo sus propios estudios siguiendo el paradigma del Dilema del Prisionero), pero ello no convierte a los autores de los estudios experimentales y a los defensores de la metodología cuantitativa en esbirros del poder explotador y opresor.

Huelga decir que todos los procesos implicados en estos estudios tienen un funcionamiento acorde con el tipo de sociedad, grupo y situación en las que se hacen presentes, pero ello no puede servir de excusa para desconocerlos o minusvalorarlos. No es desechable todo este conocimiento; tiene mucho de bueno, decía Martín-Baró en el Prólogo a Sistema, grupo y poder, aunque su pretensión de crear un conocimiento de validez universal pueda ser tildado de provinciano (Martín-Baró, 1989a, p. 5). Por otra parte, pretender que la conducta humana no es, en alguna medida, predecible, es condenarla al arbitrio, a la suerte, al destino o a la voluntad de cualquier instancia sobrenatural, y condenar al sujeto a la resignación y a la pasividad; es decir, encadenarlo al fatalismo.

Las relaciones entre conocimiento y poder son bien conocidas, pero es muy posible que se hayan desorbitado en manos del construccionismo. Tomás Ibáñez, uno de sus más genuinos representantes, presta una atención especial a este aspecto: si no es posible construir conocimiento sobre lo social sin que lo social quede afectado, "debemos admitir que cualquier científico social que sea realmente eficaz en tanto que científico (...) está actuando ineludiblemente como agente político" capaz de incidir sobre la realidad social (Ibáñez, 1992, p. 23). De nuevo una sentencia apodíctica que deja un escaso margen para el acuerdo. La reducción de la realidad social a la realidad política ya resulta, en sí misma, problemática, sobre todo cuando esa realidad la definimos en términos microsociales, que son los más estrictamente psicosociales.

El apoyo prestado por el conocimiento científico social a distintas formas de dominación es un hecho difícilmente rebatible; también lo es, como acabamos de señalar, su contrario; pero al mismo tiempo, cabría preguntarse por el sentido de un conocimiento sobre lo social si lo social no quedara afectado (un conocimiento etéreo, vagando en el vacío), de la misma manera que cabría preguntarse por el sentido que tendría el conocimiento sobre determinados aspectos de nuestra salud si esta no se viera positivamente afectada, o todavía peor, si creyéramos, como insinúa el construccionismo al negar validez a la observación empírica, que no hay mayor veracidad en un diagnóstico médico que en el horóscopo. Actuar como un agente político puede ser un objetivo manifiesto del científico social, pero también una consecuencia inevitable del resultado de sus teorías e investigaciones o del uso que se haga de ellas, el corolario imprescindible de la imposibilidad de asepsia y de neutralidad intrínseca a la misma actividad científica (una postura moral), o una intención atribuida por parte de los actores políticos (politización del conocimiento social). 
La naturaleza política de las teorías psicosociales puede adquirir, pues, diversos rostros, todos igualmente legítimos, pero no todos igualmente susceptibles de ser considerados, definidos y agrupados bajo la etiqueta de "agentes políticos”. En el caso de Martín-Baró, por ejemplo, así como el de todos sus compañeros asesinados en 1989, fue una postura moral $\mathrm{y}$, sobre todo, una interesada y manipulada atribución por parte del poder político y económico salvadoreño. En la Introducción a Acción e ideología lo dejaba explicitado en un tono casi profético: corre peligro la vida de quienes "pretenden iluminar los problemas que están a la raíz del conflicto o contribuir a la búsqueda de su solución” (Martín-Baró, 1983). Por otra parte, como hemos señalado en algún otro momento, "su noción de compromiso no fue servil a ninguna fuerza política", ni se sostuvo sobre el poder político; fue antes y mucho más un compromiso moral que un compromiso político (De la Corte, 2001, p. 216), aunque eso no le impediría pensar que la manera en la que venía desarrollando su actividad teórica acercaba su psicología social (su psicología de la liberación) a una psicología de la acción cuyas consecuencias se adentran, de manera inevitable, en el campo de las decisiones políticas (Martín-Baró, 1989a, p. 7).

No obstante, la acción política, entendida como una acción que refuerza o desafía el orden político instituido, no es la única manera de incidir sobre la realidad social ni la estrategia que ha utilizado la intervención a la hora de hacer productivo el conocimiento psicosocial. Ello supondría un empobrecimiento del propio concepto de poder y una injustificada renuncia a una mirada psicosocial en los términos propuestos por Cartwright (1959), French y Raven (1974), Raven (1992) o Thibaut y Kelley (1959): el poder como influencia persuasiva y no como imposición en el sentido weberiano. Para incidir sobre la realidad social, no es necesario actuar como un agente político.

$\mathrm{Si}$, a título de ejemplo, tomamos como marco de referencia algunos de los manuales sobre intervención psicosocial publicados en los últimos años (Blanco \& Rodríguez Marín,
2007; Fernández, Morales, \& Molero, 2011; Hombrados, 2013; Maya, García, \& Santolaya, 2007) y revisamos las distintas intervenciones que en ellos se contienen, podemos observar: a) que el componente político se podría intuir en casos como la intervención social y comunitaria en el ámbito de la inmigración, la intervención psicosocial con menores en situación de desprotección, la prevención del consumo de drogas en la población juvenil o en los programas para mejorar el acceso a los servicios sociales de personas sin techo; b) que en casos como el proyecto de prevención de SIDA en trabajadores temporeros, atención a niños con asma en Nueva York, una intervención comunitaria para incrementar la donación de sangre en un campus universitario, la implementación de un programa para demorar el inicio de la actividad sexual en adolescentes, el desarrollo del sentido de comunidad, o internet y cambio comunitario en un barrio empobrecido de Chicago, hay que hacer un ejercicio muy imaginativo para encontrarlo; c) que en ninguno de los programas llevados a cabo, los agentes de intervención han actuado como agentes políticos ni se han servido del poder político y d) que el poder puesto en práctica ha sido el poder de recompensa, el poder de experto o el poder de información, de acuerdo con la taxonomía propuesta por French y Raven (1974).

No parece, pues, que todas estas intervenciones estén inspiradas por un agente político, persigan el mantenimiento del statu $q u o$, o estén al servicio de una minoría dominante interesada en seguir ahondando en la desigualdad, en la injusticia social o en la opresión política. Tampoco parece que haya sido ese el Leitmotiv de Lewin, Milgram, Asch, Tajfel, Sherif, Zimbardo, entre los clásicos, o de Susan Fiske, John Bargh, Richard Petty o John Dovidio, entre los investigadores de referencia más actuales. Eso sería como pensar que el uso de la metodología cuantitativa lleva impreso dentro de sí, como una necesidad intrínseca, ponerse al servicio del poder opresor para dar cobertura a sus fechorías.

La monografía Psicología social crítica e intervención psicosocial. Reflexiones y experiencias 
de investigación (Moncayo \& Díaz, 2015) no nos desvela, pese al título, la contribución que hace la psicología social crítica de raíz construccionista a la intervención. Entre los 14 capítulos que la conforman, se alude de manera general a algunas intervenciones, pero no se describe ninguna de ellas en los términos consensuados al efecto: problema que se aborda, participantes en la intervención, actividades desarrolladas, resultados y evaluación de la intervención propiamente dicha. Lo más cercano a este esquema tan elemental es el capítulo de Claudia Jurado en el que se describen algunas actividades llevadas a cabo en organizaciones campesinas paneleras, pero se hace como acompañamiento secundario a la historia de las organizaciones campesinas en Colombia, a las distintas visiones de la participación o al desarrollo teórico de los conceptos de cooperación y participación (Jurado, 2015).

Por lo que respecta a la investigación, tan solo el capítulo de Obando, Betancourt y Martínez (2015) sobre los imaginarios patriarcales en torno al género femenino cabe ser considerado como una "experiencia de investigación" propiamente dicha, con la salvedad de que las autoras se limitan a comentar los resultados de un interesante estudio llevado a cabo por dos de ellas en 2010. El resto de la monografía está dedicado a reflexiones y especulaciones teóricas sobre lo psicosocial (los cuatro primeros capítulos), la psicología social crítica, la diferencia entre atención psicosocial e intervención psicosocial, con una particularidad que llama poderosamente la atención: a lo largo de las numerosas reflexiones sobre lo psicosocial se prescinde de referentes como George H. Mead, Kurt Lewin, Muzafer Sherif, Henri Tajfel, Gordon Allport, Solomon Asch, Stanley Milgram, Philip Zimbardo, etc., por mencionar tan solo a algunos de los más conocidos y reconocidos. Probablemente, se trate de uno de esos "falsos dilemas" que no ha sido capaz de superar una parte de la psicología social de habla hispana: el que opone una psicología reaccionaria a una psicología progresista.

Sirva a este respecto la advertencia que hiciera Ignacio Martín-Baró hace casi cuarenta años: "lo que hace reaccionaria o progresista a una teoría no es tanto su lugar de origen cuanto su capacidad para explicar u ocultar la realidad y, sobre todo, para reforzar o transformar el orden social" (Martín-Baró, 1998, p. 294). Tampoco es el método, cabría añadir, el que define como reaccionaria o progresista una manera de abordar los procesos psicosociales. En definitiva, la lectura de esta monografía no arroja luz sobre cuáles son las novedades que aporta la psicología social crítica a la teoría tradicional en torno a la naturaleza de lo psicosocial o a la intervención psicosocial más allá de los manidos tópicos sobre la construcción social de la subjetividad y la crítica a la metodología cuantitativa.

\section{El mundo de lo real (La realidad) como "a priori" existencial}

Si la huella de la realidad históricosocial es real y cómo podemos conocerla (qué es lo real y cómo podemos conocerlo) es la pregunta que Berger y Luckman se plantean en las primeras páginas de La construcción social de la realidad. La respuesta que avanzan está en perfecta sintonía con las posiciones epistemológicas que nos vienen acompañando desde el comienzo de este artículo (la síntesis kantiana entre entendimiento -racionalismo- y sensibilidad empirismo-, la síntesis dialéctica de Vygotski, la filosofía galileana de Lewin, la relación entre espíritu y naturaleza de Horkheimer, la definición de lo psíquico -la subjetividad- por parte de Mead, y el realismo crítico de Martín-Baró). Es decir, se trata de una respuesta que se aleja de manera decidida de los dualismos excluyentes a los que han acabado sucumbiendo las posturas idealistas (el constructivismo social entre ellas) y positivistas desoyendo las recomendaciones de la principal figura de la filosofía moderna (Kant). Y lo hacen además apoyándose en dos referentes de contrastada y compartida autoridad, Durkheim y Weber, para darle la razón a ambos.

Los hechos sociales son cosas (Durkheim) y son significados (Weber). Se trata de dos supuestos que no se contradicen: la sociedad "posee facticidad objetiva" al tiempo que se 
asienta sobre un conjunto de actividades que "expresan un significado subjetivo". Ambos eran conscientes del carácter dual de lo social. El resultado no es el recogimiento de la realidad social en los reservados del sujeto ensimismado, sino la existencia visible de una realidad sui géneris (Berger \& Luckman, 1968, p. 35) erigida (construida) sobre el significado que hemos convenido en darle a los elementos que la conforman. Esos significados adquieren facticidad objetiva a través de la habituación, de la repetición de actos de acuerdo con el sentido otorgado a los componentes de la situación estimular y de la existencia de pautas de comportamiento que se reproducen de manera más o menos automática "con economía de esfuerzos" por parte del sujeto (Berger \& Luckman, 1968, p. 74). La habituación proporciona, pues, un trasfondo estable a la actividad humana y constituye el antecedente necesario de la institucionalización de las pautas socioculturales y de los marcos estructurales; de esa estructura que, al adquirir, como hecho inherente a ella, regularidad y estabilidad, perfecciona una cualidad que ya existía en su germen: la objetividad de sus componentes, de suerte que pasan a experimentarse como algo que existe "por encima y más allá de los individuos [...] y como si poseyeran una realidad propia, que se presenta al individuo como un hecho externo y coercitivo" (Berger \& Luckman, 1968, p. 80).

Así, cuando se dice, con razón, que hay formas de comprensión negociada de la realidad que tienen un significado crítico en la vida social en la medida en que están conectadas con actividades en las que están implicadas las personas (supuesto 4 del construccionismo social: Gergen, 1985, p. 268), parece obvio que estamos hablando de significados subjetivos dotados de facticidad objetiva debido a su tipificación recíproca, fuente y origen de su estabilidad y regularidad (de su institucionalización) y a sus consecuencias sobre los interlocutores convirtiéndose, así, al mismo tiempo, en resultado de la construcción humana y en condición preexistente al sujeto.

La relación dialéctica entre el hombre (el productor) y el mundo social (el producto) también supone que "el producto vuelve a actuar sobre el productor" (Berger \& Luckman, 1968, p. 83), que las instituciones también tienen la capacidad de controlar el comportamiento humano "estableciendo pautas definidas de antemano, que lo canalizan en una dirección determinada" (p. 76). Este hecho es el que permite hacer predicciones respecto al comportamiento y formular a partir de ahí estrategias de intervención, tanto a nivel individual como colectivo (comunitario). El ser humano piensa, construye y actúa sobre la realidad en la misma medida en que la realidad piensa, interpreta y actúa respecto al ser humano a través de los modelos de relación interpersonal e intergrupal definidos y puestos en práctica por los otros, por el homo socius que todos llevamos dentro.

Entra de nuevo en escena la existencia de un a priori existencial que, dicho de la manera más comedida, enmarca las formas y los contenidos del conocimiento (del pensamiento) y de la acción humana haciéndolas a veces necesarias y obligatorias gracias a la constancia y regularidad coercitiva de algunos de los componentes del orden y la estructura social. Martín-Baró lo expresaría de manera algo más terminante en uno de sus trabajos de juventud previamente mencionados: "podríamos decir que el hombre, por el hecho de serlo, se encuentra con una circunstancia existencial a priori. Es decir, el hombre, sin que de su parte ponga o quite nada, se encuentra arrojado a un mundo. Existir es, ante todo, una referencia, al mundo" (MartínBaró, 2016, p. 127) ${ }^{4}$, pero no a un mundo en abstracto, sino a unas condiciones de vida que el propio autor concretó en los estudios llevados a cabo en el Instituto Universitario de la Opinión Pública (IUDOP). En definitiva, "cada persona elabora su existencia a partir de un sistema social que encuentra ya como dato previo [...]. Así, cada sistema social es al mismo tiempo un dato previo y un producto humano" (Martín-Baró, 1989a, p. 49).

La naturaleza construida del orden y de la estructura social no impide, pues, que algunas de sus manifestaciones terminen adquiriendo dimensiones reales sui géneris. Muchas de ellas se presentan a los órganos de los sentidos en 
unos términos muy cercanos a como lo hacen los objetos del orden natural. Pongamos un ejemplo para entendernos. De acuerdo con los datos ofrecidos por el Grupo de Memoria Histórica (GNMH), entre 1958 y 2012 el conflicto armado colombiano causó la muerte de, al menos, 220.000 personas (Centro Nacional de Memoria Histórica [CNMH], 2013, p. 20). Sería un error pensar que este es un hecho perteneciente al mundo de la naturaleza. Será fácil convenir que se trata más bien de un dato incontestable (un hecho objetivo), que se sitúa, por derecho propio, en el espacio de la realidad social; de esa realidad empedrada de significados que poseen facticidad objetiva (seres reales que no son materia, recordando de nuevo a Martín-Baró).

El discurso de los actores armados está plagado de excusas y justificaciones; "para ellos, la población es señalada como una prolongación del enemigo"; son sus "bases sociales", "colaboradores", "traidores", etc. (CNMH, 2013, p. 38). Significados convertidos en hechos, que han segado la vida de cientos de miles de personas en Argentina, El Salvador, Guatemala o Chile. El conocido teorema de William Thomas nos desvela el secreto: "si los individuos definen las situaciones como reales, éstas acaban siendo reales en sus consecuencias". Robert Merton consagra este teorema como uno de los grandes hitos de la ciencia social, porque "es aplicable instructivamente a muchos, si es que no a la mayor parte, de los procesos sociales" (Merton, 1964, p. 419). Las interpretaciones que las personas hacen de las situaciones sociales y de sus protagonistas tienen su continuación en las acciones, interacciones y relaciones mutuas que estas llevan a cabo. Tanto es así, que una definición originalmente falsa (los estereotipos, sin ir más lejos) puede acabar convirtiéndose en verdadera debido a las consecuencias comportamentales que ella misma genera. Recuérdese a este respecto el amplio rango de fenómenos sociales asociados a las llamadas profecías autocumplidas analizados por Merton.

Los objetos con mente que somos los humanos se caracterizan por su capacidad de crear, aprender, utilizar y transmitir significados, y para atribuirles a los otros esas mismas cualidades. El desarrollo de la conciencia del significado es la clave de la subjetividad, dirá George H. Mead. Pero ese desarrollo solo el posible bajo una condición: los otros. Los socii, tanto a nivel personal como, sobre todo social (el "otro generalizado": la comunidad o grupo social organizados), se convierten así en pre-condición de la conciencia, en condición necesaria para incorporar a la conciencia el significado de las cosas, de suerte que "el proceso del cual surge la persona es un proceso social que involucra la interacción de los individuos del grupo e involucra la pre-existencia del grupo" (Mead, 1972, p. 193), y es ahí cuando, sin necesidad de perder su carácter subjetivo, el significado pasa convertirse en un hecho social en los términos del Durkheim de Las reglas del método sociológico: hechos que "no tienen al individuo por sustrato", que "reproducen, en parte, un modelo colectivo" y se reconocen por el "poder de coerción externa que ejercen o son susceptibles de ejercer sobre los individuos" (Durkheim, 1978, p. 36).

El otro generalizado dota al significado de objetividad; lo hace por la vía de las consecuencias que su puesta en práctica en las relaciones interpersonales tiene para las personas. Así lo entiende Charles Morris en la introducción a la publicación más conocida de Mead (Espíritu, persona y sociedad), aunque no la más significativa de su producción teórica:

[...] en el grado en que lo que el individuo hace o dice es entendible, aceptable o cierto para cualesquiera otros individuos involucrados en una actividad común (y sin actividad común no habría comunidad de significación), en ese grado lo que es hecho o dicho tiene un nuevo tipo de universalidad; universalidad social. Tal universalidad es, en un sentido del término, un sinónimo de objetividad. (Morris, 1972, p. 41)

Esa es la objetividad que ha convertido en hechos reales (empíricamente comprobables) el significado de "judío/a", "yihadista" "subversivo/ a”, "mujer”, "afroamericano/a”, "infiel”, “tutsi”, "inmigrante" y un innumerable etcétera. Como acertadamente apuntan Gergen, Josselson y Freeman (2015), todos ellos son hechos 
del lenguaje, que han servido para oprimir, discriminar, dominar, etc., pero cuando lo han hecho han dejado de ser una mera representación simbólica subjetiva para convertirse en hechos pertenecientes a una realidad social que, a través de la habituación, la repetición y la institucionalización poseen, en parte, facticidad objetiva en los términos de Berger y Luckman (1968).

El sentido, la dirección y la urgencia de la crítica no ha de extrañar, pues, que la pasión por la realidad se convirtiera en uno de los hechos fundantes de la ciencia social (Nisbet, 1969), que el ser humano haya sido definido como "un animal de realidades" (Zubiri), que la principal fuente de luz sea la realidad, y que esta se convierta en marco y condición de la verdad (Ellacuría), que sea la realidad la que tiene que buscar a los conceptos y no al revés (Martín-Baró), que el objeto de la psicología social sea el estudio de "la realidad cotidiana tal y como es vivida por la mayoría de la población centroamericana y, más particularmente, salvadoreña" (MartínBaró, 1983, p. 4). Cuando, siguiendo el argumento de Kenneth Gergen, sostiene que es necesario "situar y fechar el conocimiento psicosocial" a fin de "no pretender vender como universal lo que es local y parcial" (MartínBaró, 1983), no está poniendo en tela de juicio la facticidad objetiva de los hechos sociales ni mostrando su renuncia a la observación empírica a favor del análisis del discurso.

Todo lo contrario: puesto que es "la historia social concreta la que da sentido a la actividad humana en cuanto ideológica", lo que está proponiendo es definir, primero, los contornos del mundo de lo real, desvelar posteriormente el entramado de ideas que le sirven de apoyo y justificación (el fondo ideológico), para dar finalmente un paso hacia la práctica (intervención) liberadora, lo cual "no es lo mismo que afirmar que la psicología social es o deba ser simplemente historia" (Martín-Baró, 1983, p. 25). Todo ello con el objetivo de hacer una psicología social "científica" pero sin perder "la referencia a un contexto y situación concretas".
En el caso que nos ocupa, esa realidad estaba empedrada de situaciones de miseria en las que "la mayor parte del pueblo nunca ha tenido satisfechas sus necesidades más básicas de alimentación, vivienda, salud y educación” (Martín-Baró, 1998, p. 162); plagada "de negaciones, carencias, presiones incontroladas fuerzas incontrolables" (MartínBaró, 1998, p. 131); atravesada por una violencia que pasó a formar parte (y así sigue en la actualidad) "del funcionamiento normal de las estructuras sociales” (Martín-Baró, 1983, p. 376) y definida por el "carácter explotador y opresivo de las estructuras sociales", que condenan al ciudadano de a pie a una situación infrahumana (Martín-Baró, 1998, p. 208). Todas estas, y algunas otras, son las vicisitudes del proceso social que caracterizó a la sociedad salvadoreña. Pero contrariamente a lo que postula el tercero de los supuestos del movimiento construccionista (Gergen, 1985, p. 268), estas vicisitudes no se limitan a las reglas interpretativas de una comunidad de lectores (Gergen, 1996, p. 316), sino que han mostrado una demoledora validez empírica plagada de negatividad (pobreza, represión política, violencia, muerte).

Martín-Baró nunca desconfió epistemológicamente de la realidad, sino de su condición fatalista, injusta, opresora; es decir, de su condición victimaria. La realidad (naturalmente construida) como principio epistemológico: esa es la clave del realismo crítico que posiciona a Martín-Baró en un escenario epistemológico alejado del construccionismo social. Recordémoslo una vez más para despejar dudas:

Que no sean los conceptos los que convoquen a la realidad, sino la realidad la que busque a los conceptos; que no sean las teorías las que definan los problemas de nuestra situación, sino que sean esos problemas los que reclamen y, por así decirlo, elijan su propia teorización. Se trata, en otras palabras, de cambiar nuestro tradicional idealismo metodológico en un realismo crítico. A los psicólogos latinoamericanos nos hace falta un buen baño de realidad, pero de esa misma realidad que agobia y angustia a las mayorías populares. (Martín-Baró, 1998, p. 314). 
Nos encontramos en las antípodas de los repertorios interpretativos subjetivos que pretenden reducir la realidad a juegos del lenguaje: índice de hacinamiento residencial en distintas colonias de San Salvador, personas asesinadas por motivos políticos a manos de las Fuerzas Armadas entre 1978 y 1979 (MartínBaró, 2016, pp. 321-359), población civil asesinada por causas políticas entre 1980-1982 (Martín-Baró, 1983, p. 361), nivel de desempleo entre la población salvadoreña (Martín-Baró, 1998, pp. 305-308), situación de pobreza en Centroamérica (Martín-Baró, 1998, p. 324), índice de polarización política (Martín-Baró, 2003, pp. 139-155), etc. Esas son algunas de las dimensiones de la realidad que sirven de base y fundamento al realismo crítico; esa es la realidad que le impediría renunciar a la noción de verdad. Sus antecedentes no hay que buscarlos en el construccionismo, sino en la teoría marxista y, a su través, en la teoría crítica de la Escuela de Frankfurt, en la filosofía de la realidad histórica de Ignacio Ellacuría y, por descontado, en la Teología de la Liberación.

La perspectiva crítica en la que se instalan estos autores tiene como punto de partida la existencia de una facticidad objetiva (hechos procedentes del orden y de la estructura social) y subjetiva (significados para mantenerla y reproducirla), que produce víctimas frente a cuya indefensión, desamparo y sufrimiento personal y social no resulta posible la indiferencia (primacía del ser sobre el pensar), sino un intento de revertir la situación (los hechos y los significados) que los provoca (primacía de la praxis), rechazando así las dicotomías excluyentes (rechazo de los dualismos) y dibujando un modelo de sujeto socio-histórico, un sujeto que no vaga en el vacío pertrechado de repertorios interpretativos personales, sino que, al formar parte del orden y de la estructura macro y microsocial, comparte esos repertorios y, en determinados momentos, llega a naturalizarlos.

Lejos de las especulaciones en el vacío social a que da lugar el reinado absoluto del yo sobre las condiciones sociales y materiales de su existencia, el pensamiento crítico de Horkheimer y Martín-Baró está definitivamente marcado por el sufrimiento humano provocado precisamente por esas mismas condiciones. "Los verdaderos individuos de nuestro tiempo son los mártires que han atravesado infiernos de sufrimiento y de degradación por su resistencia al sometimiento y a la opresión. [...]. Los mártires anónimos de los campos de concentración son los símbolos de una humanidad que aspira a nacer" (Horkheimer, 2002, p. 168). Las protagonistas del realismo crítico son las víctimas del desorden social, las víctimas de "la realidad cotidiana tal y como es vivida por la mayoría de la población centroamericana y, más particularmente, salvadoreña" (MartínBaró, 1983, p. 4) en unos términos que fueron meticulosamente analizados a través de la más elemental metodología cuantitativa (la encuesta de opinión), sin que por esa anecdótica razón alguien se atreva a acusar a Martín-Baró de haber servido a "la defensa de los intereses de los poderosos", como alguna vez se ha insinuado, de manera más bien injustificada, respecto a quienes se sirven de métodos cuantitativos en sus investigaciones (Ovejero \& Júpiter, 2011, p. 15) 5

Es más que dudoso, pues, que Martín-Baró pudiera inspirar el movimiento cualitativo, como pretenden Gergen et al. (2015, p. 5). En primer lugar, porque en sus principales investigaciones siempre se valió de métodos cuantitativos y, en segundo lugar, porque su posición crítica no pertenece a la tradición retórica de las prácticas discursivas, sino a la tradición marxista que tiene en la estructura social y en los mecanismos ideológicos que la sustentan su principal referente teórico. El objetivo de la crítica es desvelar, desenmascarar el fondo ideológico en el que encuentra apoyo, sustento y justificación un orden social que lleva dentro de sí la pobreza, la desigualdad social y numerosas formas de violencia. El intento de unir el movimiento construccionista a la Psicología de la liberación de Martín-Baró (Gergen et al., 2015) carece, pues, de fundamento.

La metodología de encuesta fue la herramienta de la que se sirvió el IUDOP, bajo la dirección del propio Martín-Baró, para analizar las condiciones de vida (vivienda, escolaridad, empleo, ingresos 
familiares, etc.), situación económica, sistema escolar, sistema de salud (problemas de salud, instituciones de salud, expectativas sobre el futuro de la salud), guerra, opiniones políticas (preferencias partidistas, disposición al voto, opinión sobre los candidatos presidenciales), etc., de la población salvadoreña. Lo que allí queda reflejado son, naturalmente, opiniones personales (la percepción e interpretación subjetiva). Ello no obstante, que el $55.2 \%$ de los habitantes de los sectores marginales vivieran en una casa hecha de bahareque y que el $26.8 \%$ careciera de agua y energía, no es una opinión, sino un hecho objetivo: "las condiciones de vida de las personas, escribía Martín-Baró en el primer capítulo de la segunda entrega del IUDOP, no son en sí mismas cuestión de opinión, sino realidades objetivas, aunque pueden constituirse en objeto de la opinión pública" (Martín-Baró, 1989b, p. 9). Hechos de este tenor los tenemos a mano con el mínimo esfuerzo. "La justicia social es una cuestión de vida o muerte. Afecta al modo en que vive la gente, a la probabilidad de enfermar y al riesgo de morir de una muerte prematura [...]. La esperanza de vida de una niña que nazca hoy puede ser de 80 años, si nace en determinados países, o de 45, si nace en otros" (Organización Mundial de la Salud [OMS], 2008, p. 1).

El reciente informe "Estado Mundial de la Infancia 2016" de Unicef, por ejemplo, afirma que "la desigualdad matará a 69 millones de niños en 15 años" y que para 2030, 167 millones de ellos vivirán en la pobreza. Estos también son hechos. Circunscribir su existencia (la de la pobreza, el hambre, las condiciones infrahumanas de vida, la carencia de los más elementales recursos de salud, etc.) a la deconstrucción subjetiva que cada quien tenga a bien hacer de ello es como ver la realidad desde la orilla, de manera perezosa, sin querer saber lo que ocurre en el mar embravecido de su interior. Esa es, dice Lucien Febvre, uno de los nombres propios de la historiografía moderna, la actitud adoptada por algunos historiadores bajo la influencia de la epistemología posmoderna, y esa parece ser la actitud del construccionismo social. El extremo relativismo que las acompaña acaba convertido en escepticismo, “y el escepticismo justificado como objeción a toda teoría es una teoría suicida" (Ortega y Gasset, 1983, p. 158).

No ha sido precisamente este el caso de quienes han defendido los acontecimientos y productos de la historia como la principal dimensión del conocimiento social. No sería el caso, desde luego, de Marx, pero tampoco lo fue de Mannheim y, sobre todo, de Merton cuyas bases existenciales del conocimiento solo pueden ser comprendidas a la luz de los productos históricos por excelencia: la estructura social y la cultura (véanse, por ejemplo, los capítulos "El estímulo puritano a la ciencia" o "La ciencia y el orden social"). Tampoco sería el caso de Vygotski, aunque es bien sabido el alto precio que tuvo que pagar por priorizar la cultura frente a la estructura. Tampoco lo sería de Martín-Baró. La presencia de la estructura social es una constante a lo largo de toda su trayectoria, desde comienzos de la década de los sesenta cuando en "Sufrir y ser" invoca la naturaleza apriorística de las circunstancias existenciales (Martín-Baró, 2016, pp. 105-163) hasta la década de los ochenta cuando traza los lineamientos de su Psicología de la liberación y aborda las raíces estructurales de la guerra (la lucha de clases, la polarización social y la mentira institucionalizada) y sus consecuencias sobre la salud mental (el trauma psicosocial). Esas circunstancias existenciales le habían permitido, siendo un joven estudiante de Filosofía, rechazar de plano "todo apriorismo esencialista": puesto que no "no hay una esencia que pueda abarcar ni definir la existencia humana, llegamos a la conclusión de que cada existente es su existencia; es decir, existiendo, el hombre llega a ser" (Martín-Baró, 2016, p. 125).

La relación entre esencia y existencia nos remite a Marx, un autor sin el que resulta prácticamente imposible entender la propuesta de Martín-Baró, Teo (2015) cita a Marx entre los antecedentes teóricos de la psicología crítica. Como era esperable, Gergen (1985) no lo tiene en cuenta a la hora de delinear los fundamentos del construccionismo social. Esa relación nos remite, más en concreto, al Prólogo de la "Contribución a la Crítica de la Economía Política". Recordemos una vez más el tan reiteradamente citado supuesto: son las 
condiciones materiales ("el modo de producción de la vida material") las que condicionan la vida social y la subjetividad; "no es la conciencia del hombre la que determina su ser, sino, por el contrario, el ser social es lo que determina su conciencia" (Marx, 1973, p. 518).

Martín-Baró retoma esta conocida cita en un epígrafe dedicado a la estructura social perteneciente al capítulo en el que va desentrañando las características del desorden social al que se ve arrojada una parte importante de la población salvadoreña. Es en ese desorden, y debido precisamente a él, donde ahondan sus raíces el carácter, el fatalismo, la violencia y la guerra, la polarización, la salud mental y el trauma psicosocial. Respecto a todas estas secuelas del (des)orden social, dice Ellacuría, no cabe la mudez ontológica, sino denuncia (tomar conciencia de la negatividad) y utopía (tomar conciencia de la posibilidad de superarla). La primera pone sobre el tapete un tema clásico en la ciencia social: su aspiración moral, que Nisbet (1969) observa nítidamente en sus padres fundadores: "los grandes sociólogos jamás dejaron de ser filósofos morales" (p. 34). Si partimos de que "la Psicología es, tanto o más que otra ciencia, una tarea fundamentalmente ética" (Martín-Baró, 2016, p. 185), tampoco los profesionales de esta disciplina, con independencia del método del que nos sirvamos en nuestras investigaciones, dejaremos de ser, modestamente, filósofos morales. Y mientras no se demuestre lo contrario (y nadie lo ha hecho hasta el momento), no hay razón alguna para negarle ese compromiso a Lewin, Asch, Allport, Milgram, Tajfel, Zimbardo, Moscovici, Sherif, Mead, Fiske, Jost y un largo etcétera.

El compromiso social, que es, a la postre, un compromiso moral, es tan evidente en el Lewin que investiga los estilos de liderazgo como en Susan Fiske, cuando estudia el sexismo benevolente. Tildar este elenco de estudios de una "experimentación socialmente vacía" por el mero hecho de estar apoyada en datos empíricos (Ovejero \& Ramos, 2011, p. 11) es una de las cómodas falacias en las que se ha instalado el construccionismo social, muchas veces sin un real conocimiento de causa.

El principio emancipación ha pasado a formar parte constitutiva de nuestro quehacer, tanto en términos de investigación como en el marco de la intervención. No es este el momento de describir con detalle los pormenores del debate en torno a la ilusa libertad de valores en el quehacer de la ciencia social, sino de recordar que la crítica al orden social existente y a sus más lacerantes consecuencias sobre la vida y la existencia de determinadas personas forma parte de la teoría crítica de Horkheimer (1974, 2002), del realismo crítico de MartínBaró (1998) y de la psicología crítica (Teo, 2015) cuyo referente en este apartado (pp. 248-249) no es precisamente el construccionismo social, sino los dos autores recién mencionados (Max Horkheimer y Martín-Baró): "los psicólogos críticos no aceptan las estructuras actuales de la sociedad como realidades fijas" (p. 249) porque parten de supuestos claramente ajenos al construccionismo social: a) la existencia y la preeminencia de la estructura social (el a priori existencial); b) la imposible neutralidad respecto a los temas de los que nos ocupamos en la investigación (la violencia de género, la exclusión social, el racismo, la guerra, el terrorismo, la pobreza y un largo etcétera): "resulta absurdo y aun aberrante pedir imparcialidad a quienes estudian la drogadicción, el abuso infantil o la tortura” (Martín-Baró, 1998, p. 317), bien entendido que esta parcialidad moral no está reñida con la objetividad que demanda cualquier proceso de investigación y c) la posibilidad y necesidad de cambio.

La denuncia y la utopía son los dos pasos necesarios y complementarios en la lucha por los derechos humanos: "la denuncia sin utopía es, hasta cierto punto, ciega, pero la utopía sin denuncia es prácticamente inoperante, más aún, eludidora del compromiso real" (Ellacuría, 1990, p. 592). Denuncia de lo que está haciéndose y esperanza y acción hacia lo que está por hacer (utopía), porque "la verdad de la realidad no es lo ya hecho; eso es solo una parte de la realidad. Si no nos volvemos a lo que está haciéndose y a lo que está por hacer, se nos escapa la verdad de la 
realidad" (Ellacuría, 1990, p. 599). Martín-Baró, que bebió de las fuentes filosóficas y teológicas de Ellacuría, ahonda en esta distinción: junto a los "hechos", los "por hacer". La teoría crítica tiene puesta su mirada en el futuro; no se limita a reflejar la realidad tal y como es: "una ciencia que se quiera histórica debe mirar tanto al pasado como al futuro y, por tanto, no puede contentarse con reconstruir más o menos fielmente lo que se da, sino que debe esforzarse por construir aquello que no se da, pero debiera darse; no los hechos, sino los por hacer" (Martín-Baró, 1998, p. 333).

Los "hechos" (y los significados, cabría añadir) y los "por hacer" son el marco en el que se inscribe la psicología social crítica de MartínBaró. Su interés se centra en el cambio y en la transformación social, en la promoción de nuevas formas de vida social a resulta de las cuales emergerán nuevos modelos de relación interpersonal e intergrupal, en recuperar el protagonismo de las condiciones de la existencia (el ser) frente al pensar, en defender la unidad de teoría y praxis y concederle a esta última un papel preeminente. La psicología crítica pretende mejorar la vida humana no solo mediante la aplicación de las herramientas psicológicas tradicionales, o a través de la reflexividad, sino "mejorando también las condiciones reales en las que se desenvuelve la vida de las personas sin descartar la lucha por la justicia social, económica y ambiental” (Teo, 2015, p. 250), en la convicción de que la psicología "se define a sí misma como un intento científico por transformar los actos y comportamientos personales y grupales, y en la tensión entre el ser y el deber ser se asienta su ética" (Martín-Baró, 2016, p. 187).

El pensamiento crítico no se conforma con un simple papel de notario mudo de la realidad; no se limita a describir los hechos tal y como son, sino que tiene claro el objetivo de "cuestionarlos radicalmente" para transformarlos, porque "una ciencia que, en una independencia imaginaria, ve la formación de la praxis, a la cual sirve y es inherente, como algo que está más allá de ella, y que se satisface con la separación del pensar y el actuar, ya ha renunciado a la humanidad" (Horkheimer, 1974, pp. 270-271).

\section{Conclusiones}

La principal hipótesis del construccionismo social, a saber, que los términos en los que venimos a conocer el mundo y a relacionarnos con él son resultado de relaciones de intercambio activo y cooperativo entre las personas (Gergen, 1985), ha formado parte del pensamiento social desde, al menos, La pobreza de la filosofía de Carlos Marx, publicada en 1846. Como es obvio, esas relaciones se enmarcan siempre dentro de un contexto sociohistórico que acaba jugando un papel decisivo en el desarrollo de la subjetividad. La relación de interdependencia y mutua influencia entre la realidad sociohistórica y el desarrollo y funcionamiento de las funciones psíquicas superiores y de las diversas manifestaciones del comportamiento humano, que parece arrogarse el construccionismo social, forma parte de la más clásica y más sólida tradición psicosocial, la de, entre otros, Vygotski, Lewin, Mead, Milgram, Tajfel, Moscocivi, Asch, Zimbardo, Kelman y, por supuesto, Martín-Baró.

Todos ellos, desde tradiciones teóricas, posiciones epistemológicas y experiencias sociohistóricas diferentes, coinciden en la defensa de la interacción, intercambio, interdependencia y mutua influencia entre los distintos niveles de realidad que conforman la existencia del sujeto, de manera especial entre la realidades diferenciales que nos definen y caracterizan como personas y los escenarios macro y microsociales en los que se desenvuelve nuestra existencia, huyendo con ello de dualismos excluyentes en los que se había debatido la teoría del conocimiento hasta la Crítica de la razón pura, cuando Kant intenta congraciar la sensibilidad (la capacidad de recibir representaciones de los objetos; vale decir, la presencia y la influencia de una realidad externa al sujeto de la acción) y el entendimiento (la capacidad de construir ideas y pensamientos al margen de la experiencia; vale decir, la interpretación subjetiva de dicha realidad).

Cuando Gergen sostiene que no es la experiencia la que define los términos de los que nos servimos para conocer el mundo, no hace otra cosa que volver a Kant, pero vuelve 
a medias: acepta la existencia de una "razón extraempírica", pero niega la existencia de un conocimiento "reglado por los objetos" y con ello acaba posicionándose de manera clara al lado de la perspectiva endogénica. Es decir, vuelve a la filosofía prekantiana, y con ello a la absolutez de un sujeto cognoscente capaz de bastarse a sí mismo, dando pie con ello al error de pretender explicar la totalidad de los procesos sociales refiriéndose únicamente a su génesis en la psique del individuo (Mannheim, 2004). La recuperación de la realidad sociohistórica en el desarrollo de la subjetividad por parte del construccionismo social se ha visto desprovista de dos de sus principales rasgos: el hecho de que dicha realidad es compartida, y que está inevitable y necesariamente acompañada de una estructura. Es precisamente ahí donde reside un principio de objetivación, donde Berger y Luckman encuentran la "facticidad objetiva" de los hechos sociales en unos términos que dejan poco lugar a la especulación: cuando el orden social se institucionaliza, se experimenta como algo que preexiste al sujeto, como un hecho externo con capacidad de coerción, siguiendo con ello la línea marcada por Durkheim en su clásica definición de los hechos sociales.

En esa misma dirección y en ese mismo sentido, Martín-Baró invoca la existencia de un "a priori existencial" definido por las condiciones materiales y sociales en las que se desenvuelve la vida de las personas, que lo sitúan lejos de los supuestos del construccionismo social. Ese es el marco que le sirve para desarrollar sus principales aportaciones teóricas: la violencia, el fatalismo, la salud mental y el trauma psicosocial. Todas ellas tienen como marco de referencia la estructura social, un contexto macro y microsocial que las posibilita, las refuerza, las envuelve en razones justificadoras y las transmite de generación en generación como si se tratara de un hecho enraizado en la propia naturaleza del sujeto. Así es como la guerra civil salvadoreña se entiende en el marco de la lucha de clases, el fatalismo como la interiorización de la dominación social, la salud mental como "la materialización en una persona del carácter humanizador o alienante de un entramado de relaciones sociales" (Martín-
Baró, 2003, p. 338) y el trauma psicosocial como la "consecuencia normal de un sistema social basado en relaciones sociales de explotación y opresión deshumanizadoras [...], como parte de una "normal anormalidad' social" (Martín-Baró, 2003, p. 295). Ese es el marco (el desorden) social que propicia la creación de víctimas, convirtiéndose así en objeto de denuncia y de cambio.

\section{Referencias}

Aceros, J. C. (2011). Social construction and relationalism: A conversation with Kenneth Gergen. Universitas Psychologica, 11(3), 1001-1011. Recuperado de http://revistas.javeriana.edu.co/index.p $\mathrm{hp} / \mathrm{revPsycho/article/view/1001}$

Allport, G. (1962). La naturaleza del prejuicio. Buenos Aires: Eudeba.

Asch, S. (1964). Psicología social. Buenos Aires: Eudeba.

Berger, P., \& Luckman, T. (1968). La construcción social de la realidad. Buenos Aires: Amorrortu.

Blanco, A., \& Rodríguez Marín, J. (Coords.). (2007). Intervención psicosocial. Madrid: Pearson.

Cartwright, D. (1959). Field theretical conception of power. En D. Cartwright (Ed.), Studies in social power (pp. 183-220). Ann Arbor, MI: Institute for Social Research.

Centro Nacional de Memoria Histórica. (2013). iBASTA YA! Colombia: memorias de guerra y dignidad. Bogotá: Autor.

Corte, L. de la (2001). Memoria de un compromiso. La psicología social de Ignacio Martín-Baró. Bilbao: Desclée de Brouwer.

Deutsch, M. (1999). A personal perspective on the development of social psychology in the twentieth century. En A. Rodríguez \& R. Levine (Eds.), Reflections on 100 years of experimental social psychology (pp. 1-34). Nueva York: Basic Books.

Dilthey, W. (1985). Crítica de la razón histórica. Barcelona: Península. 
Dijksterhuis, A. (2010). Automaticity and the unconscious. En S. T. Fiske, D. T. Gilbert \& G. Lindzey (Eds.), Handbook of social psychology (pp. 228-267). Hoboken, NJ: Wiley.

Dovidio, J. F. (2001). On the nature of contemporary prejudice: The third wave. Journal of Social Issues, 57, 829-849. http:// dx.doi.org/10.1111/0022-4537.00244

Durkheim, E. (1978). Las reglas del método sociológico. Madrid: Akal.

Ellacuría, I. (1990). Historicidad de la salvación cristiana. En I. Ellacuría \& J. Sobrino (Eds.), Mysterium Liberationis (Vol. 1, pp. 323-373). San Salvador: UCA Editores.

Fernández Christlieb, P. (2011). Lo psicosocial. En A. Ovejero \& J. Ramos (Coords.), Psicología social crítica (pp. 48-57). Madrid: Biblioteca Nueva. Recuperado de https://ialnet.unirioja.es/servlet/articul o? codigo $=3664499$

Fernández, I., Morales, J. F., \& Molero, F. (Coords.). (2011). Psicología de la intervención comunitaria. Bilbao: Desclée de Brouwer.

French, J., \& Raven, B. (1974). Las bases del poder social. En D. Cartwright \& A. Zander (Eds.), Dinámica de grupos. Investigación y teoría (pp. 285-297). México: Trillas.

Gergen, K. (1973). Social psychology as history. Journal of Personality and Social Psychology, 26, 309-320. http://dx.doi.org/10.1037/h00 34436

Gergen, K. (1985). The social constructionist movement in modern psychology. American Psychologist, 40, 266-275. http://dx.doi.org/ 10.1037/0003-066X.40.3.266

Gergen, K. (1996). Realidades y relaciones. Aproximaciones a la construcción social. Barcelona: Paidós.

Gergen, K. (2015). An invitation to social construction (3. $\stackrel{\mathrm{a}}{\mathrm{e}} \mathrm{ed}$.$) . Los Angeles: Sage.$

Gergen, K., Josselson, R., \& Freeman, M. (2015). The promises of qualitative inquiry. American Psychologist, 70, 1-9. http://dx.doi .org/10.1037/a0038597

Glick, P., \& Fiske, S. T. (1996). The ambivalent sexism inventory: Differentiating hostile and benevolent sexism. Journal of Personality and Social Psychology, 70, 491-512. http://dx.doi.org/10.1037/0022-3 514.70.3.491

Haney, C., \& Zimbardo, P. (1998). The past and the future of U.S. Prision Policy. Twenty-five years after the Stanford prision experiment. American Psychologist, 53, 709-729. http://d x.doi.org/10.1037\%2F0003-066X.53.7.709

Hombrados, M. I. (2013). Manual de psicología comunitaria. Madrid: Síntesis.

Horkheimer, M. (1974). Teoría crítica. Buenos Aires: Amorrortu.

Horkheimer, M. (2002). Crítica de la razón instrumental. Madrid: Trotta.

Ibáñez, T. (1992). Prólogo. En D. Páez, J. Valencia, J. F. Morales, B. Sarabia \& N. Ursúa, Teoría y método en psicología social (pp. 9-29). Barcelona: Anthropos.

Jiménez Burillo, F. (1997). Notas sobre la fragmentación de la razón. Madrid: Universidad Complutense de Madrid.

Jiménez Burillo, F. (2005). Contribución a la crítica de la teoría psicosocial imperante. Encuentros en Psicología Social, 3, 5-32.

Jost, J., \& Banaji, M. (1994). The role of stereotyping in system-justification and the production of false consciousness. British Journal of Social Psychology, 33, 1-27. http://dx.doi.org/10.1111/j.2044-830 9.1994.tb01008.x

Jost, J., Banaji, M., \& Nosek, B. (2004). A decade of system justification theory: Accumulated evidence of conscious and unconscious bolstering of the status quo. Political Psychology, 25(6), 881-919. Recuperado de http://www.psych.nyu.edu/jost/Jost, \%20Banaji,\%20\&\%20Nosek $\% 20(2004) \% 20$ A\%20Decade\%20of \%20System\%20Justificati.pdf

Jurado, C. (2015). Emergencias participativas de las organizaciones campesinas paneleras en el departamento de Caldas. Una visión de la psicología social-comunitaria. En J. E. Moncayo \& A. Díaz (Eds.), Psicología social crítica e intervención psicosocial. Reflexiones y experiencias de investigación (pp. 171-190). Cali: Editorial Bonaventuriana. 
Kant, I. (1994). Crítica de la razón pura. Barcelona: Orbis.

Lewin, K. (1991). Epistemología comparada. Madrid: Tecnos.

Latané, B., \& Darley, J. (1971). The unresponsive bystander: Why doesn't he help? Englewood Cliffs, NJ: Prentice Hall.

Lippitt, R., \& White, R. (1973). Estudio experimental del liderazgo y de la vida de grupo. En H. Proshansky \& B. Seidenberg (Eds.), Estudios básicos de psicología social (pp. 641-660). Madrid: Biblioteca Nueva.

Mannheim, K. (2004). Ideología y utopía. Introducción a la sociología del conocimiento. México: Fondo de Cultura Económica.

Martín-Baró, I. (1983). Acción e ideología. Psicología social desde Centroamérica. San Salvador: UCA Editores.

Martín-Baró, I. (1989a). Sistema, grupo y poder. Psicología social desde Centroamérica II. San Salvador: UCA Editores.

Martín-Baró, I. (1989b). La opinión pública salvadoreña (1987-1988). San Salvador: UCA Editores.

Martín-Baró, I. (1998). Psicología de la liberación. Madrid: Trotta.

Martín-Baró, I. (2003). Poder, ideología y violencia. Madrid: Trotta.

Martín-Baró, I. (2016). El realismo crítico. Fundamentos y aplicaciones. San Salvador: UCA Editores.

Marx, C. (1973). Prólogo de la "Contribución a la Crítica de la Economía Política”. En C. Marx \& F. Engels, Obras Escogidas (Vol. 1, pp. 516-520). Moscú: Editorial Progreso.

Maya, I., García, M., \& Santolaya, F. (2007). Estrategias de intervención psicosocial. Madrid: Pirámide.

Mead, G. H. (1964). The definition of the psychical. En A. Reck (Ed.), Selected writings George Herbert Mead (pp. 25-59). Chicago: University of Chicago Press.

Mead, G. H. (1972). Espíritu, persona y sociedad desde el punto de vista del conductismo social. Barcelona: Paidós.

Merton, R. (1964). Teoría y estructura social. México: Fondo de Cultura Económica.
Merton, R. (1977). La sociología de la ciencia. Madrid: Alianza.

Milgram, S. (1980). Obediencia a la autoridad. Bilbao: Desclée de Brouwer.

Miller, G. (1969). Psychology as a means of promoting social welfare. American Psychologist, 24, 1063-1075. http://dx.doi.or $\mathrm{g} / 10.1037 / \mathrm{h} 0028988$

Moncayo, J. E., \& Díaz, A. (Eds.). (2015). Psicología social crítica e intervención psicosocial. Reflexiones y experiencias de investigación. Cali: Editorial Bonaventuriana.

Morris, C. (1972). George H. Mead como psicólogo y filósofo social. En G. H. Mead, Espíritu, persona y sociedad desde el punto de vista del conductismo social (pp. 23-48). Barcelona: Paidós.

Moscovici, S. (1976). Social influence and social change. Londres: Academic Press.

Nisbet, R. (1969). La formación del pensamiento sociológico. Buenos Aires: Amorrortu.

Obando, O. L., Betancourt, J., \& Martínez, D. M. (2015). Imaginarios patriarcales sobre el género femenino en comerciales televisivos colombianos. En J. E. Moncayo \& A. Díaz (Eds.), Psicología social crítica e intervención psicosocial. Reflexiones y experiencias de investigación (pp. 255-280). Cali: Editorial Bonaventuriana.

Organización Mundial de la Salud. (2008). Subsanar las desigualdades sociales. Ginebra: Autor.

Ortega y Gasset, J. (1983). Obras completas de José Ortega y Gasset. Madrid: Fundación Ortega y Gasset.

Ovejero, A., \& Ramos, J. (2011). Introducción. En A. Ovejero \& J. Ramos (Coords.), Psicología social crítica (pp. 11-24). Madrid: Biblioteca Nueva.

Ratner, C. (2015). Recuperación y promoción de las ideas de Martín-Baró sobre psicología, cultura y transformación social. Teoría y Crítica de la Psicología, 6, 48-76. Recuperado de http://www.teocripsi.com/ojs/index.php/ TCP/article/view/29/38

Raven, B. (1992). A power/interaction model of interpersonal influence: French and Raven 
thirty years later. Journal of Social Behavior and Personality, 7(2), 217-244. Recuperado de http://psycnet.apa.org/record/1993-013 70-001

Rodríguez, R., Rodríguez, A., \& Leyens, J. P. (2003). La dimensión emocional del prejuicio: isienten los miembros de los otros grupos igual que nosotros? En J. F. Morales \& C. Huici (Coords.), Estudios de Psicología Social (pp. 55-81). Madrid: UNED.

Semin, G., \& Smith, E. (2013). Socially situated cognition. Social Cognition, 31, 125-146. htt p://dx.doi.org/10.1521/soco.2013.31.2.125

Sherif, M., \& Sherif, C. (1953). Groups in harmony and tension. Nueva York: Harper.

Teo, T. (2015). Critical psychology. A geography of intellectual engagement and resistance. American Psychologist, 70, 243-254. http://d x.doi.org/10.1037/a0038727

Thibaut, J., \& Kelley, H. (1959). The social psychology of groups. Nueva York: John Wiley.

Thomson, L., \& Fine, A. (1999). Socially shared cognition, affect, and behavior: A review and integration. Personality and Social Psychology Review, 3, 278-302. http:// dx.doi.org/10.1207/s15327957pspr0304_1

Vygotski, L. (1995). Historia del desarrollo de las funciones psíquicas superiores. En L. S. Vygotski, Obras Escogidas (Vol. 3, pp. 11-325). Madrid: Visor. (Trabajo original publicado en 1931)

\section{Notas}

* Artículo de reflexión.

1 En un apasionado artículo, Carl Ratner sostiene la idea de que la "Nueva Psicología de la Liberación" que interpreta a MartínBaró desde el construccionismo social, contradice la Psicología de la liberación de este autor en los siguientes aspectos: a) articula conceptos que contradicen las palabras de Martín-Baró; b) omiten (ignoran) conceptos importantes manejados por el autor; c) tergiversan sus ideas citándolas erróneamente y presentándolas de forma incompleta y descontextualizada y d) convierten las cuestiones psicosociales concretas en abstracciones indefinidas y anodinas (Ratner, 2015, p. 60).

2 El profesor Jiménez Burillo, conocedor como pocos de los secretos epistemológicos de la psicología social, lo resumía en unos términos muy concisos: "lo que se ventilaba [iya a finales del siglo XIX!] era si los nuevos conocimientos sobre el individuo y la sociedad debían desarrollarse por el seguro camino de la Ciencia Natural o, por el contrario, deberían más bien utilizar unas formas de conocimiento diferentes, más apropiadas para sus objetos humanos" (Jiménez Burillo, 1997, p. 30).

3 Jost y Banaji (1994, pp. 1-2) ofrecen un listado de líneas de investigación empírica que han mostrado cómo las personas buscan (y normalmente encuentran) justificaciones de los acontecimientos sociales, de sus propias actitudes, sentimientos y acciones, algunas de ellas claramente dañinas para otras personas, de la conducta agresiva y discriminatoria tanto hacia miembros del propio grupo como, sobre todo, respecto a personas pertenecientes a otros grupos, de su posición social así como de la posición social de los otros, y de las condiciones de ventaja y prevalencia social. Véase también el monográfico de Social Cognition, 2011, 29(3) sobre la cognición social al servicio del statu quo.

4 Con su original estilo, Pablo Fernández Christlieb, de quien no se conocen debilidades positivistas, se suma al a priori existencial, aunque sin aludir a su naturaleza objetiva: "por fuerza, la situación debe aparecer primero que las personas y cosas que la ocupan, porque de otro modo no tendrían dónde estar: todos tienen que estar en algún lado, así que el lado es el primero". Y en un gesto poco condescendiente con el construccionismo social añade: "no son las gentes las que constituyen a las situaciones sino las situaciones las que constituyen a las gentes" (Fernández Christlieb, 2011, p. 52).

5 Por cierto, conviene recordar a este respecto tan anecdótico (el de la metodología utilizada en la investigación), que MartínBaró utilizó la técnica de medición más sofisticada de su época (el "path analysis") en su tesis doctoral. En relación con la metodología, lo que hace la psicología crítica es elegir el método más pertinente para 
PARA UNA PSiCOlOGía SOCIAL CRÍTICA NO CONSTRUCCIONISTA: REFLEXIONES A PARTIR DEL REALISMO...

estudiar un determinado problema, y no elegir los problemas que mejor convienen a una determinada metodología (Teo, 2015, p. 247). 